\author{
Małgorzata Krzemińska-Adamek \\ Maria Curie-Skłodowska University \\ Pl. Marii Curie-Skłodowskiej 5, 20-031 Lublin, Poland
}

\title{
Word association patterns in a second/foreign language - what do they tell us about the L2 mental lexicon?
}

\begin{abstract}
1. Introduction
Word association studies have been enjoying an established status in a number of areas where emphasis is put on studying connections between concepts in the human mind. Naturally, the areas in question include psychology and research into first language development and organisation, but in L2 contexts this paradigm began to be used relatively late. As far as L1 studies are concerned, much of the work started in the 1960s and resulted in establishing the now popularly accepted categorisation of associations into syntagmatic, paradigmatic, and phonological/clang.

Syntagmatic associations belong to a different word class than the stimulus word and form a sequential link with the prompt word, often co-occuring in collocations and grammatical expressions. Paradigmatic associations belong to the same word class as the stimulus word, and may form a sense relation with it (e.g. synonyms or antonyms) (e.g. Namei 2004, Meara 2009). Clang associations are those which resemble the prompt word in terms of (spoken) form, i.e.
\end{abstract}


they may share the same initial consonant, rhyming vowel or include similar syllables (Ervin 1961). Studies into word associations in L1 often described the so-called syntagmatic-paradigmatic shift, which is a change in the nature of associations occurring before the age of ten whereby the proportion of clang and syntagmatic responses produced by children gradually decreases and paradigmatic ones begin to appear in greater numbers. The shift is caused by a number of factors, which include a growth in cognitive maturity, semantic development and richness of learning and educational experiences (Ervin 1961, NcNeill 1970, as cited in Gabryś-Barker 2013). The article aims to discuss the findings of L1 and L2 word association studies and their potential to account for second language lexical organisation and processing.

2. Early studies into L2 word associations

While the studies of L1 language development (e.g. Ervin 1961, Deese 1965, Cronin 2002) were copious and revealed many insightful findings with regard to the organisation of concepts in semantic memory, word association research paradigm had not been used widely to probe second language mental lexicon until the turn of the $1980 \mathrm{~s}^{1}$. Pioneering research into bilingual word association behaviour, conducted mainly within The Birkbeck Vocabulary Project (e.g. Meara 1982), apart from providing basic information about the L2 associative network, delineated the methodology which can be used to answer questions concerning the differences between L1 and L2 mental lexicons. Additionally, it brought to light a number of possible limitations of word association research (Fitzpatrick 2009).

As for the findings of early research into bilinguals' word association patterns, it was observed that there are fairly systematic

\footnotetext{
${ }^{1}$ Some descriptions of L2 word associations appeared in the 1960s and 1970s, with the works of Riegel, Ramsey and Riegel (1967) and Rüke-Dravina (1971), who found that the L2 learners' responses to stimulus words differ systematically from those of native speakers. The early studies were scarce and their methodology was questioned on the grounds that idiosyncratic lists of stimulus words were used without a sound rationale behind the choice of these words, which disabled drawing generalised conclusions from research results.
} 
differences between associations produced by native speakers and language learners. The differences are summarised in Table 1 below.

Table 1. The comparison of native speakers' and non-native speakers' associations (based on Meara 1982, 2009)

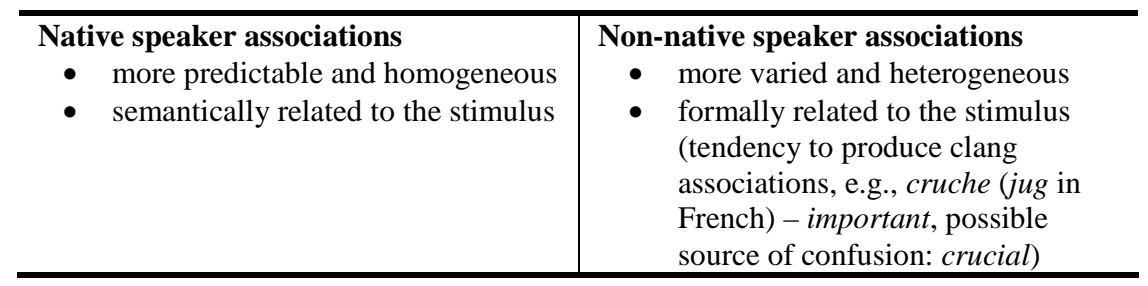

A greater heterogeneity of non-native speaker responses may come as surprising, because the learner lexicon is naturally less developed, i.e. smaller and more limited in terms of connectedness than the native speaker lexicon. A high proportion of phonologically-based associations partly explains this phenomenon, as they are less predictable than semantically-based ones. Foreign language learners tend to misunderstand a stimulus word, which leads to unusual responses, which, nevertheless, cannot be rejected as invalid. Hence the conclusion that the heterogeneous learner lexicon is organised along phonological lines. This is highly uncharacteristic of native speakers, who principally depend on semantic connections in their vocabulary networks.

The findings of the Birkbeck Vocabulary Project have been extensively referred to in various sources describing lexical processes in L2 (e.g. Carter 1987, Channell 1988), although more recent data have challenged the view of the second language lexicon suggested by Meara and colleagues. Singleton (1999), for example, suggests that the lexical connections in the mental lexicons of advanced L2 learners are predominantly semantico-pragmatic, and reliance on formal links, leading to generating clang associations, manifests itself in only a minority of cases, and is the only indication of the structural difference between L1 and L2 lexicons. The difference in question 
may be explained "in terms of different levels of lexical knowledge in the two languages and also, to an extent, in terms of interaction between the nature of L2 lexical knowledge and individual learner characteristics" (Singleton 1999: 236). The discrepancy in the results obtained in the course of the two studies may be due to the characteristics of the tests and the stimulus words used. Stimulus words of low frequency used by Meara may have been unfamiliar to the participants and thus may have generated form-based responses. Singleton's instruments used high frequency items in the 'continuous association' approach, i.e. with participants encouraged to provide as many associations as possible within a given time limit. It is likely that the nature of the data collection instruments, not solely the characteristics of the mental lexicon, influenced the types of associations reported in the studies.

3. Major findings on L1 and L2 associative networks

Recent studies involving bilingual speakers were aimed at investigating the similarities and differences between the categories of word association responses of native and non-native speakers. Their conclusions tentatively indicate that well-developed L1 and L2 mental lexicons share many organisational characteristics. Greidanus and Nienhuis (2001), who investigated word association behaviour of advanced and very advanced learners of French as an L2, found that the more proficient group was able to provide more accurate responses than the less advanced group on a receptive word association test, where the correct responses corresponded to native speaker norms. Also Sökmen (1993) observed much similarity between learner- and native-speaker-generated associates. She reported that $90 \%$ of the stimulus words prompted non-native speakers to produce responses similar to those of native speakers. Of those, $48 \%$ shared the same primary responses (i.e. supplied most often). Furthermore, Sökmen (1993) observed a growing maturity in more advanced learners' responses, resulting mainly from a richer lexicon, which manifested itself in a significant proportion of affective responses, fewer antonyms, contrasts and nonsense responses. 
More evidence supporting the claim that non-native speakers' associative networks begin to resemble native speaker patterns with a growth in L2 proficiency was supplied by Zareva (2007), who explored intermediate and advanced EFL learners' responses vis-à-vis native speakers' associative behaviour. The data obtained were analysed with respect to both quantitative and qualitative features of the mental lexicon, presented in Table 2 below.

Table 2. Quantitative and qualitative features of the mental lexicon mirrored in characteristics of word associations (based on Zareva 2007)

\begin{tabular}{lll}
\hline quantitative features & - & $\begin{array}{l}\text { strength of the associative domain (total number } \\
\text { of responses from a participant) } \\
\text { response commonality (absolute frequency of } \\
\text { responses in a group) } \\
\text { heterogeneity of responses (absolute number of } \\
\text { different responses from a participant in a group) }\end{array}$ \\
& - & proportion of syntagmatic responses \\
qualitative features & proportion of paradigmatic responses \\
& - & proportion of phonological responses \\
\hline
\end{tabular}

The main finding of the study was that the associations of both native speakers and advanced learners of English were similar in terms of quantitative features. As far as intermediate learners are concerned, the meaning connections present in their responses differed significantly from those generated by both advanced learners and native speakers. It transpires that intermediate learners' associative domain is much smaller and less diverse than that of advanced learners and native speakers, which is an indication of a lesser connectivity of the lexicon. In the case of more advanced learners and native speakers, the quantitative features are a sign of a strong and systematic interrelatedness between words in the lexicon.

Interestingly, no differences were observed between the three groups with respect to the qualitative features of lexical organisation. The groups, irrespective of proficiency, produced largely the same mean proportions of syntagmatic and paradigmatic responses. In 
addition to this, no phonological associations were found among the responses, which may be explained by the fact that the participants were only to provide associations for the stimulus words they marked as known. Zareva (2007) concludes that the degree of word familiarity rather than a loose organisation of the L2 lexicon is a determinant of proportionately more phonological than semantically-based associates in learner responses.

Zareva's (2007) study yielded surprising conclusions with regard to the proportions of paradigmatic and syntagmatic responses produced by non-native speakers. However, other explorations into learner- and native-speaker-generated associations and the effect of proficiency have produced a more consistent picture of L1 and L2 associative patterns. Native speaker responses have been found to abound in paradigmatic associations while learners seem to produce syntagmatic and clang responses in greater proportions. In a study of Norrby and Håkansson (2007), word association responses of adult learners of Swedish as a second and foreign language were compared to native responses. It was found that native speaker responses were richer in paradigmatic associations than both second and foreign language responses. The proportions of paradigmatic responses in the learners' groups were very similar, but the proportions of syntagmatic responses differed (46\% in the SL groups and 29\% in the FL group). As far as the similarities go, both learner groups produced considerable numbers of syntagmatic associations of a word-forming type, e.g. kvadrat (square) - meter (metre). Norrby and Håkansson (2007) concluded that both second language and foreign language learners are more form-focused than native speakers. The study also revealed a smaller variation in the responses of both second language learners and native speakers than in those of foreign language learners. The latter produced word association responses constituting single occurrences in the corpus of collected data, while second language learners and native speakers generated largely homogeneous associations. The findings of the study appear to validate the early claims of Meara (1982) in that foreign language learners generally 
exhibit greater variation in their word association behaviour than native speakers.

Schmitt and Meara's (1997) exploratory study also lends much support to Meara's (1982) findings, albeit not with respect to the degree of response homogeneity. They found that phonological associations were common even for stimulus words marked as known, e.g., disclose - shop, door, open; stimulate - same, equal. It seems that the forms of prompt words were mistaken for other words, causing the associations to go in a different direction than purely meaning-based. This trend can be explained by the fact that in the case of intermediate learners, meaning-based associations are only bound to become dominant with a future increase in word knowledge. Schmitt and Meara (1997) also point out that the associations generated by learners were often conceptually acceptable, but failed to be native-like. This finding may serve as evidence for the claim that vocabulary knowledge is incremental in nature, and the mastery of some of its aspects (e.g. meaning) does not necessarily entail the mastery of other aspects (e.g. the knowledge of collocations contributing to creating native-like syntagmatic associations).

The findings of the research studies presented above, concerning the change of association types with growing proficiency and a similarity between advanced L2 learners and native speakers' mental lexicons, have been questioned by a number of other research projects. It has been suggested, for example, that the knowledge of individual words rather than the level of L2 proficiency influences the types of associations generated by both native speakers and language learners. Wolter (2001), in his study of adult speakers of English as a second language and English native speakers, found that phonology plays a role in the organisation of the L2 lexicon, but only for words which are moderately known. No such effect was reported for familiar lexical items. As regards native speakers, they were able to produce more paradigmatic associations than non-native speakers, which is seen as a function of larger vocabulary size and not necessarily higher level of lexical development. Additionally, native speakers' syntagmatic associations outnumbered those generated by learners, 
which contradicts the findings of previous research. Native speakers also produced a number of clang responses, but only for words of lower frequency, which may potentially be less familiar. The main conclusion of Wolter's (2001) study is that L1 and L2 mental lexicons are not structurally similar, which is not to mean that the L2 lexicon is functionally inferior to the L1 lexicon.

In the same vein as Wolter (2001), Orita (2002) puts forward a claim that the syntagmatic-paradigmatic shift is not a characteristic feature of the entire mental lexicon, but words in a speaker's lexicon develop at their own pace and undergo individual shifts in the types of associations they elicit. The frequency of the prompt words was also found to influence the types of responses obtained. High frequency items did not generate phonological responses, even in the case of participants of low general L2 proficiency. It appears that for familiar words learners do not rely on phonological connections between items, but tend to display semantically-based links. With respect to proficiency, Orita (2002) states the actual time spent learning is more important than general command of an L2, as only longitudinal intensive exposure to language may contribute to the shift of associations towards the native speaker pattern.

\section{Limitations of word association studies}

Despite evident simplicity of use, the word association paradigm as used in L2 research has a number of downsides which may negatively influence research results. Meara (2009), for instance, laments that the L2 word association studies so far have not drawn on any theoretical models of word association behaviour in a second/foreign language. Consequently, their scope was limited in that they merely described the types of responses of L2 learners. Even those purely descriptive studies have been laden with methodological shortcomings, pertaining mainly to the categorisation of responses and choice of stimulus words.

As regards the traditional taxonomy of word associations used popularly in L1 research, which categorises participant responses into syntagmatic, paradigmatic and phonological, it has been found 
imprecise and not entirely suitable for the context of a second language. It was described as "difficult to work in practice, especially when you cannot refer to the testee for elucidation" (Meara 1982: 1), which may be a reason why in some studies the taxonomy was supplemented with additional categories or supplanted with other forms of categorisation. Greidanus and Nienhuis (2001), for example, included the category of analytic associations, which constitute defining characteristics of the stimulus words, i.e. elements used in their dictionary definitions. In other cases, a slight change in the terminology used in the study resulted in a desired broadening of association categories. Gabryś-Barker (2005), for example, used the term form associations to denote both phonological and graphic responses to a stimulus word. Schmitt and Meara (1997) abandoned the traditional categorisation and replaced it with the index of nativelikeness to rate learners' responses. Similarly, Sökmen (1993) divided the responses by word class (supra/subordinates, e.g. fruitapple; synonyms, e.g. hard-difficult; coordinates, e.g. salt-sugar; contrasts, e.g. doctor-patient; and collocations, e.g. cold-weather), and by parts of speech. Still another classification system, suggested by Fitzpatrick (2007, 2009), consists of three main categories of meaning-, position-, and form-based responses. This system is thought to add detail and specificity to the broad categories of syntagmatic, paradigmatic and clang associations, thus helping avoid unnecessary ambiguity in classifying participants' responses.

The other problematic issue in the methodology of word association studies is the selection of prompt words for a given research context. A thoughtful choice of stimuli and a sound rationale for this choice are necessary conditions for word association research, as otherwise no theoretical framework of L2 association patterns can be formulated. In Meara's words, a failure to explain thoroughly the grounds for selecting particular words for experiments "is unfortunate, because it means that discrepant results can always be explained away in terms of the stimuli used, and there is no incentive to incorporate these discrepancies into a coherent overall framework" (2009: 24). Idiosyncratic lists of prompt words are used in word association 
studies interchangeably with standard lists, the most popular of which is the 100-word Kent and Rosanoff's (1910) list. One advantage of the Kent-Rosanoff list is that it has been used successfully with native speakers and, for this reason, may serve as a useful tool of comparison in second language contexts. However, the list has also got a number of pitfalls when used in L2 research.

First of all, the Kent-Rosanoff list consists of highly frequent words, which tend to generate predictable responses, similar in L1 and L2. This could suggest that L1 and L2 lexicons share more characteristics than is actually the case (Fitzpatrick 2009). Secondly, the apparent benefit of the Kent-Rosanoff list, namely its wide use in L1 research, loses its appeal when the aims of vocabulary teaching programmes are taken into consideration. If the goals of instruction concern producing bilinguals, not "replicas of monolingual speakers", then perhaps more insights into the developing lexicon would be brought about by comparing learners with proficient bilinguals rather than with the native speaker baseline (Meara 2009: 25). Studies in which the use of frequent words as stimuli or in which frequent lexical items were used alongside less frequent ones indeed bring results indicating that frequency influences participants' word association behaviour. Less frequent words have been reported to elicit clang responses even in native speakers (Wolter 2001). Also, low-frequency items were found to elicit significantly fewer native-like associations from L2 learners, compared to frequent stimulus words (Greidanus and Nienhuis 2001). In contrast, research carried out with the use of the Kent-Rosanoff list or other sources of high-frequency items has been relatively consistent in demonstrating similarity between native and non-native associative patterns (e.g. Sökmen 1993).

\section{Conclusions}

Studies into word associations in a second/foreign language have not yielded entirely conclusive results. They have pointed out a number of tendencies in word association patterns such as a qualitative change in types of associations with an increase in general L2 proficiency or differences in types of associations according to the context of 
learning (second vs. foreign language). Some studies have also demonstrated that general level of proficiency in a foreign language is not the only factor determining the types of learner-generated associations. Individual word knowledge seems to equally heavily affect the qualitative patterns of word associations irrespective of whether native speakers or foreign language learners are taken into consideration. Despite a few attempts at deploying the word association paradigm in exploring other areas concerning second language development, for example in the assessment of productive vocabulary (Meara and Fitzpatrick 2000, Wolter 2002) or general language proficiency (Schmitt 1998), studies into L2 word association behaviour have mainly served descriptive purposes and as such have not lead to creating theoretical models of L2 word association patterns (Meara 2009). Therefore, it is vital that research into word associations in a second/foreign language be continued and performed with due methodological rigour, taking into consideration the fact that vocabulary acquisition is a dynamic process whereby words in the mental lexicon continually change their status and degree of integration in the lexical network.

\section{References}

Carter, R. (1987): Vocabulary. Applied Linguistic Perspectives. New York: Routledge.

Channell, J. (1988): Psycholinguistic considerations in the study of L2 vocabulary acquisition. In R. Carter, M. McCarthy (Eds.), Vocabulary and Language Teaching. London: Longman, 83-96.

Cronin, V. S. (2002): The syntagmatic-paradigmatic shift and reading development. Journal of Child Language 29(1), 189-204.

Deese, J. (1965): The Structure of Associations in Language and Thought. Baltimore, MD: The Johns Hopkins Press.

Entwisle, D. R. (1966): Word Associations of Young Children. Baltimore: The Johns Hopkins Press.

Ervin, S. M. (1961): Changes with age in the verbal determinants of word-association. The American Journal of Psychology, 74(3), 361-372. Retrieved from http://www.jstor.org/stable/1419742.

Fitzpatrick, T. (2007): Word association patterns: unpacking the assumptions. International Journal of Applied Linguistics, 17(3), 319-331. 
Fitzpatrick, T. (2009): Word association profiles in a first and second language: puzzles and problems. In T. Fitzpatrick, A. Barfield (Eds.), Lexical Processing in Second Language Learners. Papers and Perspectives in Honour of Paul Meara. Bristol: Multilingual Matters, 38-52.

Gabryś-Barker, D. (2005): Aspects of Multilingual Storage, Processing and Retrieval. Katowice: Wydawnictwo Uniwersytetu Śląskiego.

Gabryś-Barker, D. (2013): Association tasks in researching language learning and culture. In E. Mańczak-Wohlfeld, M. Jodłowiec (Eds.), Exploring the Microcosm and Macrocosm of Language Teaching and Learning. A Festschrift on the Occasion of $70^{\text {th }}$ Birthday of Professor Anna Niżegorodcew. Kraków: Jagiellonian University Press, 243-256.

Greidanus, T., Nienhuis, L. (2001): Testing the quality of word knowledge in a second language by means of word associations: types of distractors and types of associations. The Modern Language Journal, 85(4), 567-577.

Kent, G. H., Rosanoff, A. J. (1910): A study of association in insanity. American Journal of Insanity, 67, 317-390.

McNeill, D. (1970): The Acquisition of Language: The Study of Developmental Psycholinguistics. New York: Harper and Row.

Meara, P. (1982): Word associations in a foreign language: A report on the Birkbeck Vocabulary Project. Nottingham Linguistic Circular, 11, 29-38.

Meara, P. (2009): Connected Words. Word Associations and Second Language Vocabulary Acquisition. Amsterdam and Philadelphia: John Benjamins.

Meara, P., Fitzpatrick, T. (2000): Lex30: and improved method of assessing productive vocabulary in an L2. System, 28, 19-30.

Namei, S. (2004): Bilingual lexical development: a Persian-Swedish word association study. International Journal of Applied Linguistics, 14(3), 363-388.

Norrby, C., Håkansson, G. (2007): Girl - lass or curl? Word associations in second language learners. Australian Review of Applied Linguistics, 30(2), 22.1-22.17.

Orita, M. (2002): Word associations of Japanese EFL learners and native speakers: Shifts in response type distribution and the associative development of individual words. Annual Review of English Language Education in Japan, 13, 111-120.

Riegel, K. F., Ramsey, R. M., Riegel, R. M. (1967): A comparison of the first and second languages of American and Spanish students. Journal of Verbal Learning and Verbal Behavior, 6, 536-544.

Rüke-Dravina, V. (1971): Word associations in monolingual and multilingual individuals. Linguistics, 74(9), 66-84.

Schmitt, N. (1998): Quantifying word association responses: what is native-like? System, 26, 389-401. 
Schmitt, N., Meara, P. (1997): Researching vocabulary through a word knowledge framework. Word associations and verbal suffixes. Studies in Second Language Acquisition, 20, 17-36.

Singleton, D. (1999): Exploring the Second Language Mental Lexicon. Cambridge: Cambridge University Press.

Sökmen, A. (1993): Word association results: a window to the lexicons of ESL students. JALT Journal, 15(2), 135-150.

Wolter, B. (2001): Comparing the L1 and L2 mental lexicon. A depth of individual word knowledge model. Studies in Second Language Acquisition, 23, 41-69.

Wolter, B. (2002): Assessing proficiency through word associations: is there still hope? System, 30, 315-329.

Zareva, A. (2007): Structure of the second language mental lexicon: how does it compare to native speakers' lexical organization? Second Language Research, 23(2), 123-153. 